\title{
EXPERIMENTAL RESEARCHES ON THE VEGETAL MATERIAL QUALITY, IN ORDER TO OPTIMIZE OF SOME PROCESSING PROCESSES OF THE MEDICINAL PLANTS
}

\author{
AUGUSTINA PRUTEANU ${ }^{1 *}$, LADISLAU DAVID ${ }^{2}$, VALENTIN VLADUT ${ }^{1}$, \\ ADRIANA MUSCALU ${ }^{1}$ \\ ${ }^{1}$ National Institute of Research- Development for Machines and Installations \\ Designed to Agriculture and Food Industry - INMA, 6 Ion Ionescu de la Brad, Blv, \\ sector 1, Bucharest 71592, OP 18, Romania \\ ${ }^{2}$ University Politehnica of Bucharest, 313 Splaiul Independentei, sector 6, Bucharest \\ 060042, Romania
}

\begin{abstract}
In the production of medicinal plants, the phytotherapeutic products quality is given by the content and the amount of bioactive substances from the plant. The quality of the phytotherapeutic products is dependent on the quality of the vegetal raw material as well as by the quality of the manufacturing processes. This paper presents the experimental determinations of some physical and dimensional properties of the vegetal material, in order to separate by sorts and of obtaining of some vegetal extracts therefrom. The determinations were performed in order to optimize the separation and extraction processes of medicinal plants. Knowing the characteristics of the vegetal material is particularly important for the achievement of some high-performance technical equipment for processing of medicinal plants.
\end{abstract}

Keywords: vegetal extracts, medicinal plants fragments, properties, separation

\section{INTRODUCTION}

The species of medicinal and aromatic plants cultivated in Romania are an important basis of raw materials for the pharmaceutical industry, cosmetics, and perfumery, but also for the food industry [1]. It is important to know the biologically active substances (vitamins, alkaloids, flavonoids, saponins, tannins, bitter substances, etc.) contained in different parts of the plants (leaves, flowers, fruits, stems, herbs, roots, seeds etc.), in order to appreciate their therapeutical value [2].

Obtaining of quality finished products (volatile oils, extracts, tinctures, teas, tablets, ointments etc) from medicinal plants can be achieved by knowing the body of plant with the highest content in bioactive substances $[1,2]$, by the development of technologies and equipment for conditioning and processing in optimal conditions [3, 4], but also by knowing the main physical and dimensional properties of the vegetal material [57].

There were taken to be studied three species of medicinal plants: nettle, brotherwort, and wormwood. These have been identified and harvested from the spontaneous flora according to the morphological and biological characteristics of each species.

\footnotetext{
${ }^{*}$ Corresponding author, email: pruteanu_augustina@yahoo.com (C) 2015 Alma Mater Publishing House
} 
Further will be described morphologically and biologically the three species of medicinal plants analyzed in the paper.

The white dead nettle (Lamium album) is a species herbaceous, perennial, high of 20-50 (70) cm, with aerial stems erect or ascending, of the genus Lamium, family Lamiaceae (Labiatae), spread from the hilly area up to the alpine level. Harvesting is done before, or during the flowering, from April to September [8].

Morphological characteristics:

- the underground part: horizontally elongated rhizomes, from which start underground stolons;

- aerial stalk: develop from the stolons, has four obvious edges and is hairy, generally unbranched, empty on the inside;

- leaves: oppositely disposed, triangular-ovate limb long of 4-7 $\mathrm{cm}$ and half wide, sidelines serrated with large teeth, hairs on both sides; long petiole at the lower leaves (almost as the limb), at the upper ones reduced;

- flowers: arranged in cymes placed at the armpit of the leaves, with 3-6 white large flowers, corolla having up to $2 \mathrm{~cm}$, with the upper lip helmet shaped and the lower one spoon-shaped;

- fruitage: tiny nuts with three edges, brownish, grouped by 4 in the persistent calyx.

Herba of nettle contains the following active substances: rosmarinic acid, tannins (12-14\%), essential oil, flavonoids, mucilages [1].

The brotherwort (Thymus serpyllum) is a species of perennials, herbaceous plants, semi lignified at the bases, of the genus Thymus, family Lamiaceae (Labiatae); spread on hills, meadows or alpine pastures. Harvesting is done in the months July - August [8].

Morphological characteristics:

- the strain is ascendant and is 3-5 centimeters tall;

- leaves are small, aromatic, linear, elliptical-ovate or rounded, flat, non-toothed, petiolate, opposite, pubescent;

- flowers are arranged in verticils, grouped in capitulums or racemes; are purple or pink and cyclamen, rarely white having cylindrical-campanulate calyx with five teeth, three upper, shorts, two lower, long, floral tube short, pubescent, in the outside the corolla with ovate upper base, emarginate, fourangled.

Thymol is the main active substance contained by brotherwort, acting as a natural antiseptic, being helpful against viruses [9].

The wormwood (Artemisia absinthium) is a herbaceous perennial plant, high of $60-120 \mathrm{~cm}$ in the family Asteraceae; spread from the lowlands up to the hilly one. Harvesting is done in the June-July months [8].

Morphological characteristics:

- the leaves are compound, hairy, splitted, gray-green on the face, silver-gray on the back; the basal ones are three pinnate sectioned, with a length of up to $20 \mathrm{~cm}$ and the ones from the stalk with lengths not exceeding $10 \mathrm{~cm}$, simplifying gradually towards the top;

- the flowers are pale yellow and very smelling grouped in small flower heads;

- the fruit is an achene.

The wormwood contains the following active substances: bitter substances - temisina, volatile oil about 3-12 $\%$ composed of thujone and tuiol, azulenes, flavones, organic acids (palmitic) linoleic, oleic, lauric, stearic, nicotinic, arachidic [1].

Knowing the main physical and dimensional properties of the mixture of fragments from medicinal plants is important for the choice of the appropriate technologies for their processing, for the adequate regulation of the working bodies, for the choice of the optimal working regimes of the machine as a whole and for obtaining quality phytotherapeutic products, with high content of biologically active substances. 


\section{MATERIAL AND METHOD}

The herb of the plants was dried and then there was chopped in bulk, at the medicinal plants mincer, type TIMATIC, set to the size of $4 \mathrm{~mm}$.

Aspects with the integer plants before and after chopping is observed in the images of Figure 1.

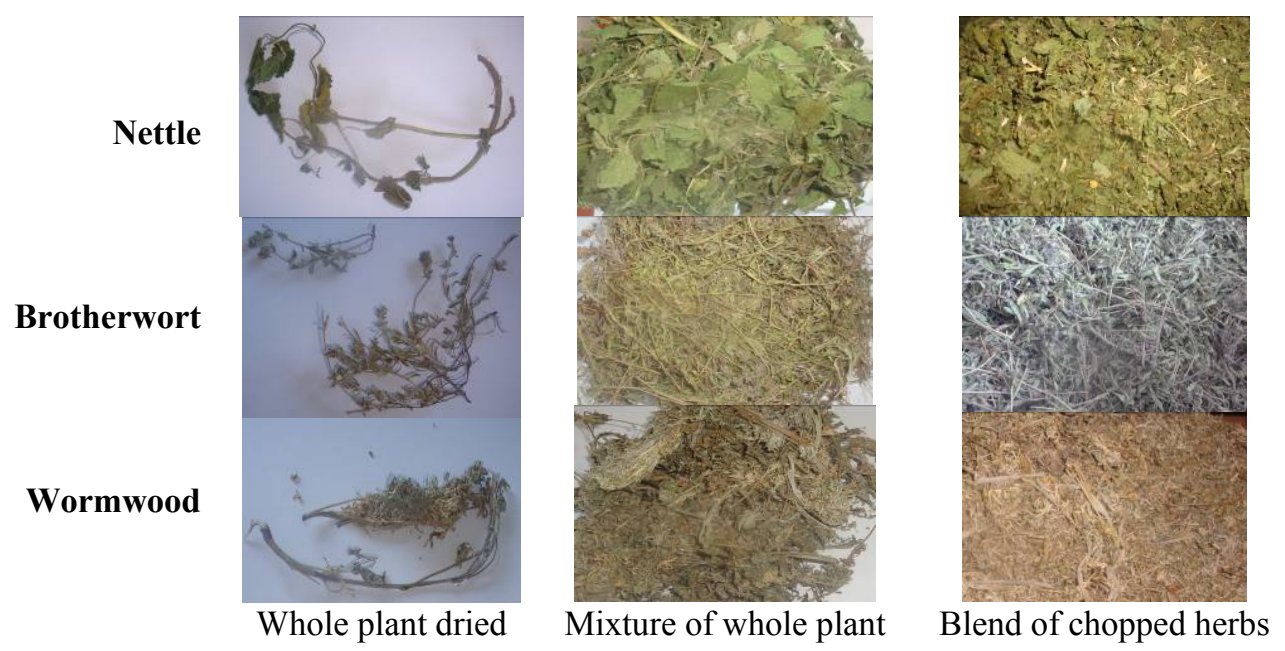

Fig. 1. Aspects of the integer plants before and after chopping.

From the physical properties of medicinal vegetal material were determined the most important: the humidity, volumic mass, density, porosity, average diameter, specific outer surface, the flow appreciated by the natural slope angle and the coefficient of static friction $[3,4,6]$. There have been groups of five samples for each determination, in the work being shown the average values of the obtained results.

The medicinal plants humidity (water content) depends on their content in bioactive substances. In the Romanian Pharmacopoeia is provided that the dried medicinal plants to have a humidity between $12 \ldots 14 \%$ [10]. To determine the moisture of the three species of medicinal plants in the dry state was used the thermobalance.

Volumic mass of the mixture of vegetal fragments is the mass of material reported to the total volume occupied by it in its natural state. For the determination of the volumic mass was used the method of the measuring cylinder.

Density is the ratio between the mass of the fragments and the absolute volume (without pores or voids) occupied by them. In this paper, the determination of vegetal fragments density was done by the method of the pycnometer. The porosity (\%) is the property of vegetal fragments of not occupy the entire storage volume, existing a space between the solid fragments. Knowing the values of the volumic mass and of the fragments density, the porosity was determined using the equation (1):

$$
\varepsilon=\left(1-\frac{\rho_{v}}{\rho}\right) \cdot 100,[\%]
$$

The porosity and density of vegetal fragments influences and the vegetal mixture stratification on the sieves surface.

The average diameter of the medicinal fragments chopped, determined with the classifier with sieves, was calculated using the equation (2):

$$
d_{m}=\frac{\sum p_{i} \cdot d_{i}}{\sum p_{i}},[\mathrm{~mm}]
$$


where: $p_{i}$ represents the percentage of material on the sieve $i$ of the classifier; $\Sigma p_{i}=100$ - the sum of percentages of material from the sieves; $d_{i}-$ the average size of the fragments of each intermediate fractions, considered as the average size of the sieve openings that fit that fraction $\mathrm{d}_{\mathrm{i}}=\left(\mathrm{l}_{\mathrm{i}}+\mathrm{l}_{\mathrm{i}+1}\right) / 2$.

The classifier sieves were chosen so as to fulfill the condition $l_{i+1}=\sqrt{2} \cdot l_{1}$, starting from the upper sieve towards the lowest sieve. The specific outer surface $\left(\mathrm{S}_{\mathrm{s}}\right)$ of a vegetal mixture of fragments represents the sum of the surrounding surfaces of all the fragments that are found in a unit mass in $\left(\mathrm{m}^{2} / \mathrm{kg}\right)$ and is calculated using the equation (3). $\mathrm{S}_{\mathrm{s}}$ occurs like a characteristic size in the processes of heat and mass exchange between fragments and environment, in problems of flow through granular layers, in the assessment of energy consumption at shredding.

$$
S_{s}=\frac{6 \cdot 10^{3}}{\rho_{s} \cdot d_{m}},\left[\mathrm{~m}^{2} / \mathrm{kg}\right]
$$

The natural slope angle is the angle that makes the free surface of a mass of vegetal material poured onto a surface with the horizontal plane [6]. For the determination of the natural slope angle was used the method of the cone of material.

The coefficient of static friction represents the ratio between the tangential force required to initiate the relative displacement of two bodies in contact each other and the normal force at their contact surfaces. The value of this coefficient depends, in general, of the materials nature of the two bodies, of the condition of the surfaces and the contact pressure between the two bodies [11].

The method by which was determined the coefficient of static friction was the usual method of the inclined plane that was applied on two types of surfaces: steel sheet and metal fabric.

Knowing the size of the coefficient of friction of the vegetal fragments on different surfaces is important because it intervenes in the process of movement fragments on various surfaces, both for their transport, and in the separation process on sieves, on inclined planes, therefore, when took place the separation with friction. Also, this coefficient is important to characterize the properties of flowing and bulk storage of the fragments.

The coefficient of static friction and the natural slope angle of the medicinal plants fragments intervene in the movement of the vegetal mixture on different types of surfaces, in the process of sorting by fractions and in the characterization of the separation process on fractions.

In the work was carried out and the granulometric analysis of each initial mixture of fragments, corresponding to each species of medicinal plant. For all the three medicinal plants were performed five samples, each sample of analyzed vegetal material from the mass of the mixture of fragments has had $120 \mathrm{~g}$. The vegetal material was sieved at the classifier with sieves, at the amplitude of $50 \mathrm{~mm}$, for 5 minutes. On each sieve was found by a quantity of plant material that represented the totality of the fragments with sizes smaller than those of the openings of the sieve of above of that considered and larger than of the considered sieve through which has passed.

For each sort (fraction) resulting from granulometric analysis were obtained extracts by maceration at cold for 40 minutes. There were weighed about 5 grams of each type, were added in vials, and there were initially wetting with $20 \mathrm{~mL}$ of petroleum ether, then there were added another $20 \mathrm{~mL}$. Then the vials with the sample were homogenized and were left to soak for one hour. After soaking, the samples were filtered through filter paper then were dried in an oven at $30^{\circ}$ for 24 hours. After drying, the samples were weighed and the differences between the initial sample masses and the masses of samples after extraction express the masses of substances extracted from every type (fraction) corresponding to each plant studied.

\section{RESULTS}

In the case of the fragments of the three species of medicinal plants analyzed, were experimentally determined five samples for each of the physical properties, which characterizes the process of separating on sieves. Table 1 presents the average values of measurements. 
The presented data highlight the influence of the nature of the vegetal mixture, of the size and geometric shape of the fragments, of the state of the surface of fragments on the sorting process. Functional and structural characteristics of the sorting equipments are influenced by the physical properties the fragments of the medicinal plants.

The dimensional characteristics provides information on the minimum and maximum sizes of the fragments from a vegetal mixture, contributing to the choice of sieves openings for each species, in order to obtain a high quality plant material. The results obtained from the dimensional analysis of the fragments of each medicinal plant analyzed were transposed graphically in Figure 2 by representing the amount of material that passed through the sieve PASSED (P) and of the REFUSAL (R) expressed as a percentage, depending on the size of the sieve openings. The values of the refusals and passed of each sieve from the package of sieves arranged one after another can be used also to determine the flow rates of the sifted and of the refusals.

Table 1. The values of physical properties of the fragments of medicinal plants.

\begin{tabular}{|c|c|c|c|c|c|c|c|c|c|}
\hline \multirow{2}{*}{$\begin{array}{c}\text { Fragments of } \\
\text { medicinal } \\
\text { plants }\end{array}$} & \multirow{2}{*}{$\begin{array}{c}\text { Humidity } \\
{[\%]}\end{array}$} & \multirow{2}{*}{$\begin{array}{c}\text { Average } \\
\text { diameter } \\
{[\mathrm{mm}]}\end{array}$} & \multirow{2}{*}{$\begin{array}{l}\text { Volumic } \\
\text { mass } \\
{\left[\mathrm{kg} / \mathrm{m}^{3}\right]}\end{array}$} & \multirow{2}{*}{$\begin{array}{l}\text { Density } \\
{\left[\mathrm{kg} / \mathrm{m}^{3}\right]}\end{array}$} & \multirow{2}{*}{$\mid \begin{array}{c}\text { Porosity } \\
{[\%]}\end{array}$} & \multirow{2}{*}{$\begin{array}{c}\text { Specific } \\
\text { surface } \\
\times 10^{3}\left[\mathrm{~m}^{2} / \mathrm{kg}\right]\end{array}$} & \multirow{2}{*}{$\begin{array}{c}\text { Natural } \\
\text { slope } \\
\text { angle, } \psi \\
\left.{ }^{0}\right]\end{array}$} & \multicolumn{2}{|c|}{$\begin{array}{l}\text { The coefficient of } \\
\text { static friction, } \mu\end{array}$} \\
\hline & & & & & & & & $\begin{array}{c}\text { Sheet } \\
\text { steel }\end{array}$ & $\begin{array}{l}\text { Metallic } \\
\text { fabric }\end{array}$ \\
\hline $\begin{array}{l}\text { Nettle } \\
\text { (herba) }\end{array}$ & 11.45 & 5.02 & 47.2 & 37.5 & 26 & 31.88 & 61.62 & $\begin{array}{c}0.645 \div \\
0.897\end{array}$ & $\begin{array}{c}0.987 \div \\
1.284\end{array}$ \\
\hline $\begin{array}{l}\text { Brotherwort } \\
\text { (herba) }\end{array}$ & 10.59 & 2.97 & 78 & 56.4 & 38 & 35.82 & 63.82 & $\begin{array}{c}0.703 \div \\
1.150\end{array}$ & $\begin{array}{l}1.005 \div \\
1.451\end{array}$ \\
\hline $\begin{array}{c}\text { Wormwood } \\
\text { (herba) }\end{array}$ & 12.17 & 3.18 & 74.8 & 51.3 & 46 & 36.71 & 65.85 & $\begin{array}{c}0.734 \div \\
0.893\end{array}$ & $\begin{array}{c}0.886 \div \\
1.149\end{array}$ \\
\hline
\end{tabular}

The variation curves of the sifted material (passed), refusal and of its distribution on the sieves depending on the size of the sieve openings for fragments of medicinal plants are shown in Figure 2.
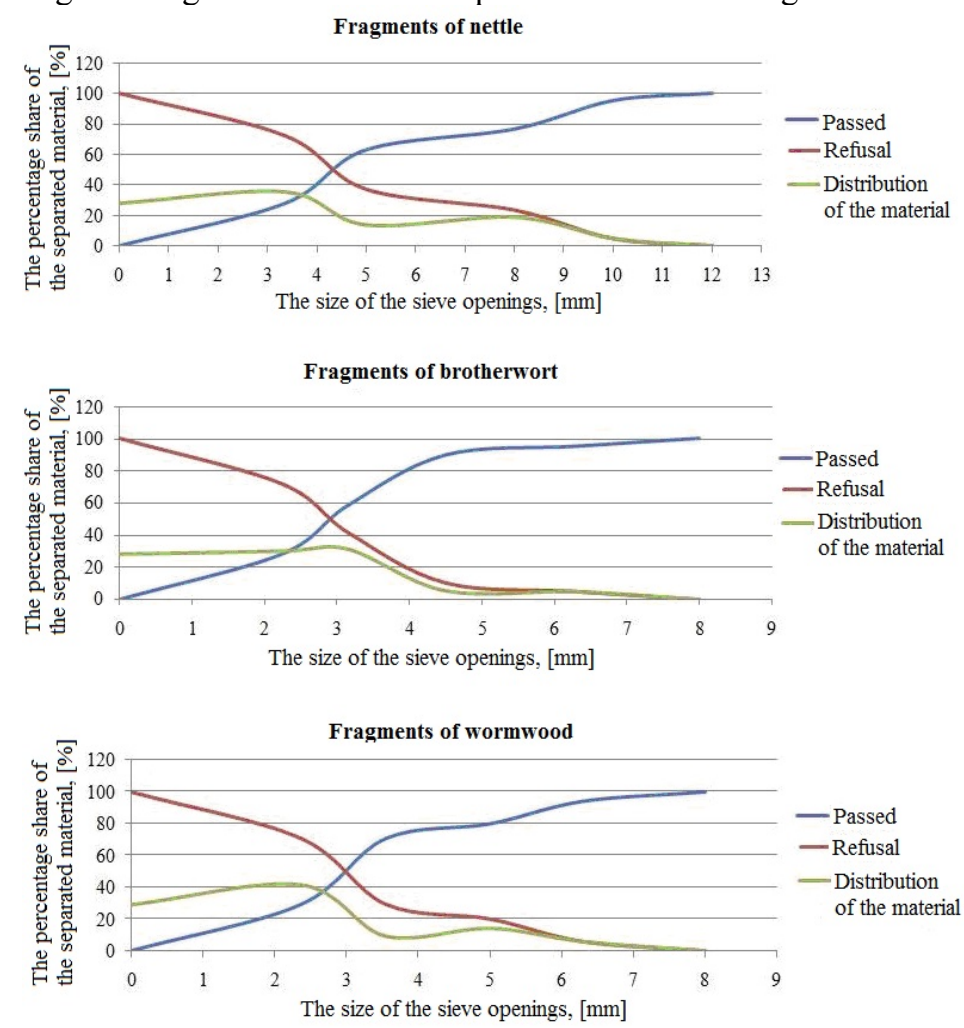

Fig. 2. The variation curves of the sifted material (passed), refusal and of its distribution on the sieves. 
These curves establish the percentage distribution of vegetal material separated from the first to the last classifier sieve with vibratory movement and can be used to select the proper sieves allowing the separation of the fragments corresponding to the desired percentage of vegetal material, in order to obtain quality plant extracts.

The content of extracted substances was calculated for each plant and respectively sort. Figure 3 shows the variation of the content in extracted substances for four sorts of fragments corresponding to each medicinal plant studied.

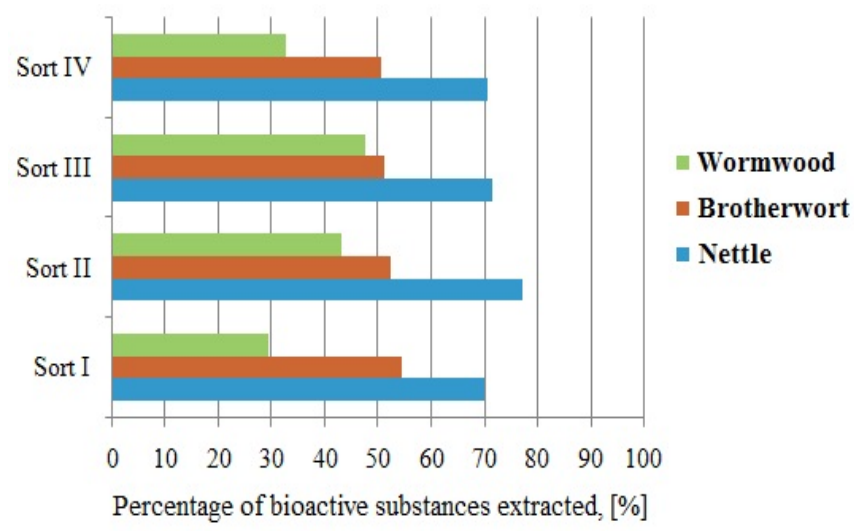

Fig. 3. The variation of the content in extracted substances for four sorts of fragments corresponding to each medicinal plant studied.

\section{CONCLUSIONS}

The experiments conducted illustrate both the dependence between the quality of separation and extraction processes of the medicinal plants as well as the values of the static friction coefficient and the fragment dimensions.

The determined static friction coefficient values fall within the limits presented in various specialty works. These were influenced by the porosity, density, volumic mass and the humidity of the vegetal material.

The smaller values on the steel sheet, compared with the higher values obtained on the sieve with openings of $4 \mathrm{~mm}$ can be due to the following aspects:

- the surface characteristics;

- the presence of the tiny hairs on the surface of the vegetal fragment. The tiny hairs may have different shapes and sizes, some are longer others shorter, some are smoother and others rougher, some are straight and others curvy sometimes causing the clamping of the fragments between them;

- the sizes of the shredded material.

From the analysis of the plant material variation curves from sieved and refusal and of its distribution on sieves, depending on the sizes of the classifier sieve openings, it can make recommendations regarding the process of sorting of the medicinal plants fragments. Taking into account the dimensions of the sieve openings and the percentage distribution of material on sieves it is observed that the nettle is the best separated on the sieve with the dimensions of the openings of $3.35 \mathrm{~mm}$, the brotherwort on the sieve with the opening up to 3.15 $\mathrm{mm}$, the wormwood can be sorted on the sieves with apertures of maximum $2.36 \mathrm{~mm}$.

Analyzing the data of Figure 3 is observed the content in bioactive substances for the sorts (fractions) of each type of plant. So the following are found:

- at nettle of the sort II with the fragments dimensions ranging between 3.4 and $4.9 \mathrm{~mm}$ was extracted the greatest amount of bioactive substances: $77.1 \%$;

- at brotherwort of the sort I with the dimensions less than $2.2 \mathrm{~mm}$ was extracted the maximum of $54.4 \%$ from $100 \mathrm{~g}$ of vegetal material dimensioned and the minimum percentage of $50.6 \%$ was recorded the sort IV; 
- at wormwood of the sort III with the dimensions ranging between 3.6 and $4.9 \mathrm{~mm}$ was extracted the greatest amount of bioactive substances: $47.5 \%$.

The knowledge of the physical and dimensional characteristics of the vegetal material is important for the optimization of the separation and extraction processes, for the realization of specialized equipment with high performances in the processing of the medicinal plants.

\section{REFERENCES}

[1] Bojor, O., Ghidul plantelor medicinale si aromatice de la A la Z, Ed. Fiat Lux, Bucuresti, 2003.

[2] Stoian, I., Savopol, E., Extracte farmaceutice vegetale, Ed. Medicala, Bucuresti, 1977.

[3] Căsăndroiu, T., Utilaje pentru prelucrarea primară şi păstrarea produselor agricole, Curs, U.P.B., Facultatea de Maşini Agricole, București, 1993.

[4] Voicu, Gh., Stefan E.M., Constantin G.A., Voicu P., Tehnologii de prelucrare a produselor agricole, Ed. Terra Nostra, Iaşi, 2013.

[5] Allen, T., Particle size analysis by sieving, Powder Sampling and Particle Size Determination, Elsevier, Ch. 4, 2003, p. 208-250.

[6] Ipate, G., Căsăndroiu, T., Proprietăţi fizice ale produselor agroalimentare; Ed. Politehnica Press, Bucureşti, 2009.

[7] KeShun, L., Some factors affecting sieving performance and efficiency, Powder Technology, vol. 193, 2009, p. 208-213.

[8] Ardelean, A., Mohan, Gh., Flora Medicinală a României, Editura All, Bucureşti, 2008.

[9] Nabavi, S. M., Marchese, A., Izadi M., Curti, V., Daglia, M., Nabavi, S. F., Plants belonging to the genus Thymus as antibacterial agents: From farm to pharmacy, Food Chemistry, vol. 173, 2015, p. 339-347.

[10] *** - Farmacopeea Română, Editia X, Editura Medicala, Bucureşti, 1993.

[11] Orăşanu, N., Voicu, Gh., Ungureanu, N., Determination of the static and dynamic friction coefficients for the milling products and their variation with respect to some parameters, Modelling And Optimization In The Machines Building Field, vol. 3, no. 15, 2009. 